\section{What is a Cameragraph?}

\author{
By Shari J. Lendy and Rebecca P. Butler
}

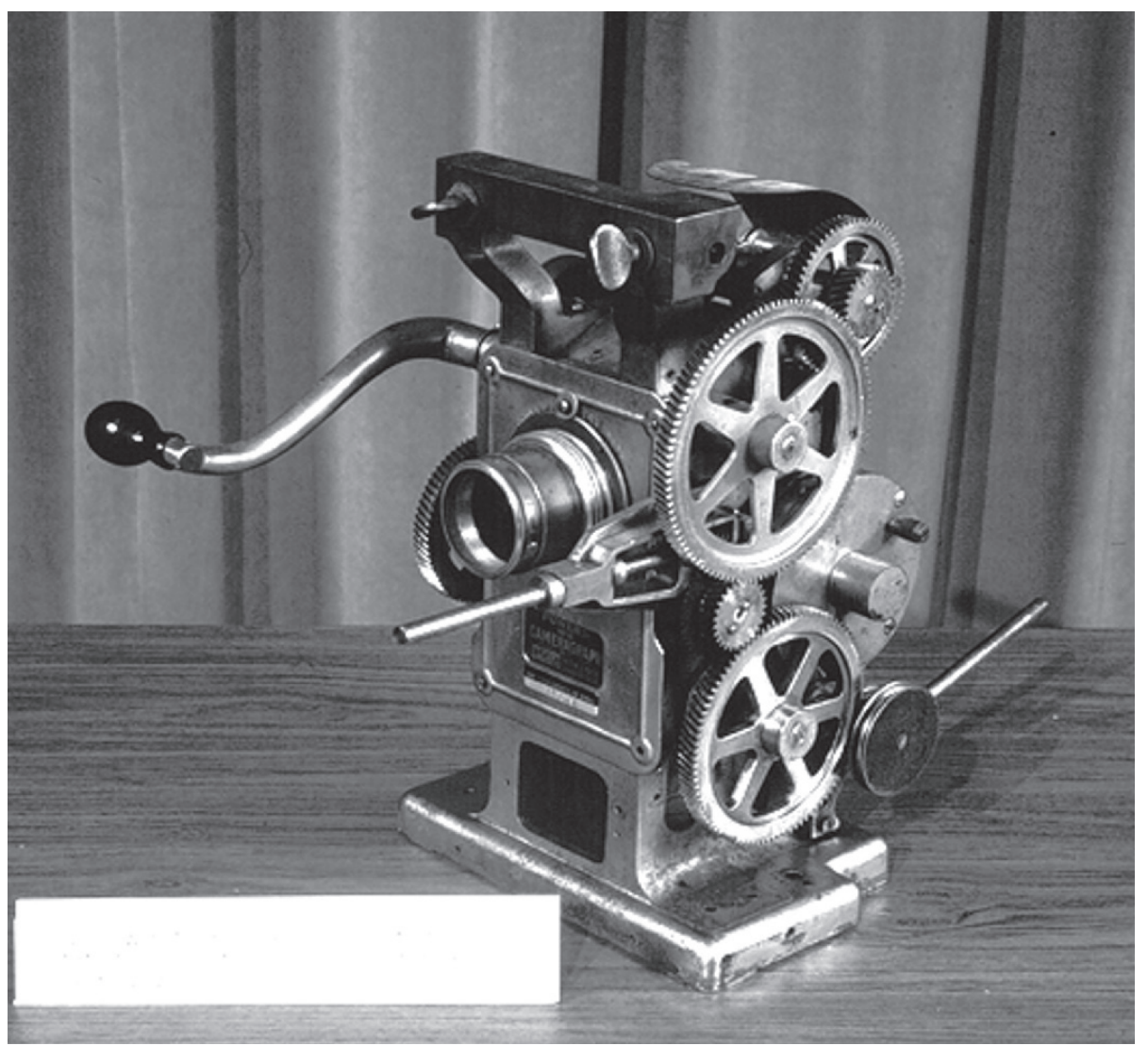

Lee and Lida Cochran AECT Archives, Blackwell Museum of Education, Northern Illinois University, 1999

The picture above is of an early film projector (pictures only) called the Powers Cameragraph No. 6. Manufactured by The Nicholas Powers Company of New York, it used 35 millimeter film, instead of the slides common to Magic Lanterns, to deliver images to a wall or screen.

The AECT Archives' Cameragraph (1910-1916) is not whole; it is essentially the machine head, that part of the film projector which holds the film and has the film-moving mechanism. An intact Cameragraph had a lamp house made of metal, to protect the projectionist from possible blindness created by stray sparks flying out of the lamp house. It also had carbon rods, used to light the lamp. These were changed every thirty minutes during viewing.

One of the technological flaws when employing these film projectors was the ingredient used to create the actual film. This ingredient, nitrate, is chemically identical to smokeless gunpowder. Linked together with the sparks often flying out of the lamp, there was always a potential for fire.

The Nicholas Powers Company was issued three patents for the Cameragraph. One was filed by inventor John Pross, who, at one time, was an employee of Thomas Edison. Pross introduced a new shutter design, which gave the projector less flicker or jump when moving. Called the Maltese Cross movement, the Cameragraph used a four-pin gear that ran through an "X" shaped slot, increasing the speed of movement between frames and giving the receiver a brighter image and less jumping with the film. (The Maltese movement is still used in cameras and film projectors today.)

\section{References}

Gage, S. (1914). Optic projection. Ithaca, NY: Comstock Publishing.

Lee and Lida Cochran AECT Archives. (1999). Powers Cameragraph No.5. DeKalb, Illinois: Blackwell Museum of Education, Northern Illinois University. Retrieved from http://www.cedu.niu.edu/blackwell/multimedia/high/VT/062.html

Rossell, D. (2005). Encyclopedia of early cinema, In Abel, R. (Ed.) Projectors (pp. 537540), New York: Routledge Publishing

United States Patent Office (2009). Retrieved from http://patimg2.uspto.gov/.piw?Doc id=00722382\&homeurl=http $\% 3 \mathrm{~A} \% 2 \mathrm{~F}$ 